\title{
Development and validation of nomograms predicting survival in Chinese patients with triple negative breast cancer
}

Yaping Yang ${ }^{1 \dagger}$, Ying Wang ${ }^{1 \dagger}$, Heran Deng ${ }^{1 \dagger}$, Cui Tan², Qian $\mathrm{Li}^{1}$, Zhanghai $\mathrm{He}^{2}$, Wei Wei ${ }^{3}$, Enxiang Zhou ${ }^{4}$, Qiang Liu ${ }^{1 *}$ and Jieqiong Liu ${ }^{1 *}$ (D)

\begin{abstract}
Background: Triple negative breast cancer (TNBC) is an aggressive and heterogeneous disease. Nomograms predicting outcomes of TNBC are needed for risk management.

Methods: Nomograms were based on an analysis of 296 non-metastatic TNBC patients treated at Sun Yat-sen Memorial Hospital from 2002 to 2014. The end points were disease-free survival (DFS) and overall survival (OS). Predictive accuracy and discriminative ability were evaluated by concordance index (C-index), area under the curve (AUC) and calibration curve, and compared with the American Joint Committee on Cancer (AJCC) staging system, PREDICT and CancerMath. Models were subjected to bootstrap internal validation and external validation using independent cohorts of 191 patients from the second Xiangya Hospital and Peking University Shenzhen Hospital between 2007 and 2012.

Results: On multivariable analysis of training cohort, independent prognostic factors were stromal tumor-infiltrating lymphocytes (TILs), tumor size, node status, and Ki67 index, which were then selected into the nomograms. The calibration curves for probability of DFS and OS showed optimal agreement between nomogram prediction and actual observation. The C-index of nomograms was significantly higher than that of the seventh and eighth AJCC staging system for predicting DFS (training: 0.743 vs $0.666(P=0.003)$ and $0.664(P=0.024)$; validation: 0.784 vs 0.632 $(P=0.02)$ and $0.607(P=0.002))$ and $O S$ (training: 0.791 vs $0.683(P=0.004)$ and $0.677(P<0.001)$; validation: 0.783 vs $0.656(P=0.006)$ and $0.606(P=0.001))$. Our nomograms had larger AUCs compared with PREDICT and CancerMath. In addition, the nomograms showed good performance in stratifying different risk groups of patients both in the training and validation cohorts.

Conclusion: We have developed novel and practical nomograms that can provide individual prediction of DFS and OS for TNBC based on stromal TILs, tumor size, node status, and Ki67 index. Our nomograms may help clinicians in risk consulting and selection of long term survivors.
\end{abstract}

Keywords: Nomograms, Disease-free survival, Overall survival, Triple negative breast cancer, Stromal tumorinfiltrating lymphocytes

\footnotetext{
*Correspondence: victorlq@hotmail.com; liujiegiong01@163.com

tYaping Yang, Ying Wang and Heran Deng contributed equally to this work.

${ }^{1}$ Guangdong Provincial Key Laboratory of Malignant Tumor Epigenetics and Gene Regulation, Breast Tumor Center, Sun Yat-sen Memorial Hospital, Sun Yat-sen University, Yanjiang West Road 107\#, Guangzhou 510120, China Full list of author information is available at the end of the article
}

(c) The Author(s). 2019 Open Access This article is distributed under the terms of the Creative Commons Attribution 4.0 International License (http://creativecommons.org/licenses/by/4.0/), which permits unrestricted use, distribution, and reproduction in any medium, provided you give appropriate credit to the original author(s) and the source, provide a link to the Creative Commons license, and indicate if changes were made. The Creative Commons Public Domain Dedication waiver (http://creativecommons.org/publicdomain/zero/1.0/) applies to the data made available in this article, unless otherwise stated. 


\section{Background}

Breast cancer is the most frequently diagnosed cancer and the leading cause of cancer death in women worldwide. It is a heterogeneous disease, and different subtypes of breast cancer show distinct clinicopathologic features, aggressiveness, response to therapies, as well as survival outcomes. Triple negative breast cancer (TNBC), the most aggressive subtype of breast cancer characterized by lack of expression of estrogen receptor (ER), progesterone receptor (PR) and human epidermal growth factor receptor 2 (HER2), has significantly poorer outcomes than non-TNBC subtypes due to the natural history of this life-threating disease and lack of endocrine and target therapies $[1,2]$. Indeed, TNBC is also a heterogeneous disease including several distinct molecular subtypes that differ in biological features, treatment response and prognosis [3]. Nomogram is an useful and convenient tool for cancer patients to quantify and predict risk and prognosis. For breast cancer patients, a lot of prognostication nomograms have been developed and validated based on traditional clinicopathological features [4-14]. However, the prognostic values of these models were only tested in a few cohorts of TNBC subgroup [6, 13, 15]. Furthermore, the majority of these models were developed based on white patients not Asian women, and only one nomogram [13] can predict recurrence risk (most models focused on overall survival or breast cancer-specific survival). Thus, nomograms for predicting recurrence risk and survival outcomes in TNBC are scarce. Stromal tumor-infiltrating lymphocytes (TILs) are recently reported to show important prognostic value in TNBC, both in the adjuvant and neoadjuvant settings [16-19]. Yet, TILs have not been included in any breast cancer prognostic models so far.

In the current study, we aimed to develop nomograms to predict the disease-free and overall survival for non-metastatic TNBC patients using clinicopathological and molecular variables as well as stromal TILs from 296 TNBC patients treated at Sun Yat-sen Memorial Hospital in China. Moreover, we externally validated the prognostic models using independent cohorts of 191 Chinese women from the second Xiangya Hospital and Peking University Shenzhen Hospital.

\section{Methods}

\section{Patient population and data processing}

The training set was based on data from 296 patients with invasive TNBC who meet the inclusion criteria diagnosed and treated at Sun Yat-sen Memorial Hospital from 2002 to 2014. inclusion criteria defined eligible women who were age 18 years or older and had diagnosed non-metastatic invasive breast cancer, had confirmed histology as defined by the American Joint Committee on Cancer (AJCC) (thresholds for defining
ER/PR negative were set at less than $1 \%$ using immunohistochemical staining), had complete follow-up, availability of tumor samples, no history of previous malignancies (except for primary skin basal cell carcinoma and squamous cell carcinoma). Totally, there were 435 non-metastatic invasive TNBC patients who were age 18 years or older treated at Sun Yat-sen Memorial Hospital from 2002 to 2014. We excluded 52 (12.0\%) patients who had incomplete follow-up information, and then removed 84 patients whose tumor samples were not available, as well as 3 women with a history of previous malignancies. For patients who underwent neoadjuvant chemotherapy and had clinically negative axillary lymph nodes, sentinel lymph node biopsy was performed before neoadjuvant therapy. And all of the pathologically node-positive patients received axillary lymph node dissection. An external validation cohort of 191 TNBC women who met the same inclusion criteria was enrolled from the second Xiangya Hospital $(n=144)$ and Peking University Shenzhen Hospital $(n=47)$ between 2007 and 2012. All patients were required to have sufficient information to score all variables in the developed nomograms. Ethical approval was obtained from participating institutions through their respective institutional review boards Ethical approval was obtained from participating institutions through their respective institutional review boards (IRB) (Sun Yat-sen Memorial Hospital Ethics Committee and IRB, Ethics Committee and IRB of Peking University Shenzhen Hospital, and Ethics Committee and IRB of the Second Xiangya Hospital, Central South University), and written informed consent was obtained from study participants.

We retrieve all relevant information on demographic data (age, marital status, family history of breast cancer), clinicopathological features (menstrual status, histological type, grade, tumor size, node status, Ki67 index), and treatment information (surgery type, receiving of radiotherapy, chemotherapy type, chemotherapy regimen) for all of the included patients. In the dataset, some variables (grade, and Ki67 index) contained missing data, which may result in biases. To compensate for this, multiple imputation methods by chained equations [20-22] to account for the missing values of variables was performed before nomogram development and validation. We have created ten multiple imputed-datasets, and variables included in the imputation model were age, marital status, family history of breast cancer, menopausal status, tumor size, node status, stage and sTIL group. The raw stromal TILs and Ki67 values were estimated using a CLIA certified lab. Stromal TILs were evaluated in hematoxylin and eosin (H\&E) sections originally sampled from each TNBC included in this study, following the criteria proposed by the International TIL WG [23]. Concisely, all mononuclear cells in the stromal compartment within the 
Table 1 Demographic and clinicopathological characteristics of patients in the training and validation cohorts before and after multiple imputation

\begin{tabular}{|c|c|c|c|c|c|c|c|c|c|}
\hline \multirow[t]{2}{*}{ Characteristics } & \multicolumn{2}{|c|}{ Trainingcohort before imputation } & \multicolumn{2}{|c|}{$\begin{array}{l}\text { Training cohort } \\
\text { after imputation }\end{array}$} & \multicolumn{2}{|c|}{$\begin{array}{l}\text { Validation cohort } \\
\text { before imputation }\end{array}$} & \multicolumn{2}{|c|}{$\begin{array}{l}\text { Validation cohort } \\
\text { after imputation }\end{array}$} & \multirow[t]{2}{*}{$P$} \\
\hline & $\bar{N}$ & $\%$ & $\bar{N}$ & $\%$ & $\bar{N}$ & $\%$ & $\bar{N}$ & $\%$ & \\
\hline Age & & & & & & & & & 0.302 \\
\hline Median (range) & $48(26-88)$ & & $48(26-88)$ & & $46(20-87)$ & & $46(20-87)$ & & \\
\hline$\leq 35$ & 35 & 11.8 & 35 & 11.8 & 25 & 13.1 & 25 & 13.1 & \\
\hline $36-50$ & 138 & 46.6 & 138 & 46.6 & 100 & 52.4 & 100 & 52.4 & \\
\hline$>50$ & 123 & 41.6 & 123 & 41.6 & 66 & 34.6 & 66 & 34.6 & \\
\hline \multicolumn{10}{|l|}{ Marital status } \\
\hline Married & 281 & 94.9 & 281 & 94.9 & & & & & \\
\hline Unmarried & 15 & 5.1 & 15 & 5.1 & & & & & \\
\hline \multicolumn{10}{|c|}{ Family history of breast cancer } \\
\hline Yes & 34 & 11.5 & 34 & 11.5 & & & & & \\
\hline No & 262 & 88.5 & 262 & 88.5 & & & & & \\
\hline \multicolumn{10}{|l|}{ Menopausal status } \\
\hline Premenopausal & 174 & 58.8 & 174 & 58.8 & & & & & \\
\hline Postmenopausal & 122 & 41.2 & 122 & 41.2 & & & & & \\
\hline Histology & & & & & & & & & 0.329 \\
\hline Ductal & 274 & 92.6 & 274 & 92.6 & 172 & 90.1 & 172 & 90.1 & \\
\hline Lobular/other & 22 & 7.4 & 22 & 7.4 & 19 & 9.9 & 19 & 9.9 & \\
\hline Grade & & & & & & & & & 0.890 \\
\hline I & 11 & 3.7 & 15 & 5.1 & 11 & 5.8 & 11 & 5.8 & \\
\hline$\|$ & 49 & 16.6 & 54 & 18.2 & 37 & 19.4 & 37 & 19.4 & \\
\hline III & 181 & 61.1 & 227 & 75.0 & 143 & 74.9 & 143 & 74.9 & \\
\hline Unknown & 55 & 18.6 & 0 & 0.0 & & & & & \\
\hline Tumor size & & & & & & & & & 0.414 \\
\hline$\leq 2 \mathrm{~cm}$ & 152 & 51.4 & 152 & 51.4 & 98 & 51.3 & 98 & 51.3 & \\
\hline $2-5 \mathrm{~cm}$ & 120 & 40.5 & 120 & 40.5 & 71 & 37.2 & 71 & 37.2 & \\
\hline$>5 \mathrm{~cm}$ & 24 & 8.1 & 24 & 8.1 & 22 & 11.5 & 22 & 11.5 & \\
\hline Node status & & & & & & & & & 0.630 \\
\hline NO & 172 & 58.1 & 172 & 58.1 & 108 & 56.5 & 108 & 56.5 & \\
\hline N1 & 73 & 24.7 & 73 & 24.7 & 54 & 28.3 & 54 & 28.3 & \\
\hline $\mathrm{N} 2+\mathrm{N} 3$ & 51 & 17.2 & 51 & 17.2 & 29 & 15.2 & 29 & 15.2 & \\
\hline Stage & & & & & & & & & 0.958 \\
\hline I & 97 & 32.8 & 97 & 32.8 & 65 & 34.0 & 65 & 34.0 & \\
\hline$\|$ & 141 & 47.6 & 141 & 47.6 & 89 & 46.6 & 89 & 46.6 & \\
\hline III & 58 & 19.6 & 58 & 19.6 & 37 & 19.4 & 37 & 19.4 & \\
\hline Ki67 index & & & & & & & & & 0.150 \\
\hline$<40 \%$ & 111 & 37.5 & 126 & 42.6 & 86 & 45.0 & 94 & 49.2 & \\
\hline$\geq 40 \%$ & 139 & 47.0 & 170 & 57.4 & 92 & 48.2 & 97 & 50.8 & \\
\hline Unknown & 46 & 15.5 & 0 & 0.0 & 13 & 6.8 & 0 & 0.0 & \\
\hline sTIL group (\%) & & & & & & & & & 0.146 \\
\hline $0-9$ & 61 & 20.6 & 61 & 20.6 & 25 & 13.1 & 25 & 13.1 & \\
\hline $10-19$ & 79 & 26.7 & 79 & 26.7 & 62 & 32.5 & 62 & 32.5 & \\
\hline $20-49$ & 85 & 28.7 & 85 & 28.7 & 60 & 31.4 & 60 & 31.4 & \\
\hline
\end{tabular}


Table 1 Demographic and clinicopathological characteristics of patients in the training and validation cohorts before and after multiple imputation (Continued)

\begin{tabular}{|c|c|c|c|c|c|c|c|c|c|}
\hline \multirow[t]{2}{*}{ Characteristics } & \multicolumn{2}{|c|}{ Trainingcohort before imputation } & \multicolumn{2}{|c|}{$\begin{array}{l}\text { Training cohort } \\
\text { after imputation }\end{array}$} & \multicolumn{2}{|c|}{$\begin{array}{l}\text { Validation cohort } \\
\text { before imputation }\end{array}$} & \multicolumn{2}{|c|}{$\begin{array}{l}\text { Validation cohort } \\
\text { after imputation }\end{array}$} & \multirow[t]{2}{*}{$P$} \\
\hline & $N$ & $\%$ & N & $\%$ & N & $\%$ & $N$ & $\%$ & \\
\hline$\geq 50$ & 71 & 24.0 & 71 & 24.0 & 44 & 23.0 & 44 & 23.0 & \\
\hline \multicolumn{10}{|l|}{ Surgery type } \\
\hline Mastectomy & 135 & 45.6 & 135 & 45.6 & & & & & \\
\hline Lumpectomy & 161 & 54.4 & 161 & 54.4 & & & & & \\
\hline \multicolumn{10}{|l|}{ Radiotherapy } \\
\hline Yes & 197 & 66.6 & 197 & 66.6 & & & & & \\
\hline No & 99 & 33.4 & 99 & 33.4 & & & & & \\
\hline \multicolumn{10}{|l|}{ Chemotherapy type } \\
\hline Neoadjuvant & $62^{a}$ & 20.9 & $62^{\mathrm{a}}$ & 20.9 & $34^{b}$ & 17.8 & $34^{\mathrm{b}}$ & 17.8 & 0.515 \\
\hline Adjuvant & 222 & 75.0 & 222 & 75.0 & 146 & 76.4 & 146 & 76.4 & \\
\hline No chemotherapy & 12 & 4.1 & 12 & 4.1 & 11 & 5.8 & 11 & 5.8 & \\
\hline \multicolumn{10}{|l|}{ Chemotherapy regimen } \\
\hline anthracycline-based & 70 & 24.6 & 70 & 24.6 & 44 & 24.4 & 44 & 24.4 & 0.622 \\
\hline taxane-based & 72 & 25.4 & 72 & 25.4 & 39 & 21.7 & 39 & 21.7 & \\
\hline anthracycline\& taxane -based & 142 & 50.0 & 142 & 50.0 & 97 & 53.9 & 97 & 53.9 & \\
\hline
\end{tabular}

Abbreviations: STIL, stromal tumor-infiltrating lymphocyte; ${ }^{a}$ The group contained 10 patients who received both neoadjuvant and adjuvant chemotherapy. ${ }^{\mathrm{b}}$ The group contained 5 patients who received both neoadjuvant and adjuvant chemotherapy

borders of the invasive tumor were evaluated and assessed as a percentage value. The scoring report did not include TILs which were outside of the tumor borderline, or around DCIS and normal tissue, or in the necrosis areas. One experienced pathologist has evaluated stromal TILs in all the cases. Ninety-eight randomly selected cases, corresponding to approximate $20 \%$ of the study population, were separately annotated by a second pathologist for assessing the inter observer consistency of the readings. The end points were disease-free survival (DFS defined as time from date of diagnosis to the local, regional recurrence, distant metastasis, contralateral breast cancer, death (including non-cancer death) or last contact (June 30th, 2017)) and overall survival (OS, calculated from date of diagnosis to the date of death or last contact (June 30th, 2017)).

\section{Statistical analysis}

Survival curves for distinct variables were generated using the Kaplan-Meier estimates and were compared using log-rank test. Prognostic factors that assessed by univariable Cox analysis were subjected to backward stepwise (which used the Akaike information criterion) Cox proportional regression analysis to identify statistically significant variables $(P<0.05)$ to be included in the final nomograms. Interaction between variables was assessed by adding interaction variable to the Cox model. We tested the interactions between ki67 and node status, ki67 and tumor size, as well as tumor size and node status.
For the calibration (modified Hosmer- Lemeshow statistic for survival analysis), the nomograms were then subjected bootstrap method [24] of leave one out prediction 1000 times for internal validation of training cohort and external validation of validation cohort by $\mathrm{R}$ statistical software, rms package. The bootstrap resampling for internal validation was performed to reduce the over-fitting bias of the model and obtain the evaluation value of more reliable prediction accuracy of the model. External validation with independent cohorts of 191 women from the second Xiangya Hospital and Peking University Shenzhen Hospital was also performed. The predictive accuracy and discriminative ability of nomograms were determined by concordance index (C-index) ( $\mathrm{C}$ index is actually a generalization of the area under the ROC curve [25]), area under the curve (AUC) and calibration curves. We compared the predictive accuracy and discriminative ability of our nomograms with the seventh and eighth AJCC staging system, and the classical PREDICT [6] and CancerMath models [9]. Comparison between two different models was according to previously described methods [26]. We compared the predicted survival with observed actual survival to calibrate the nomograms for 3-, and 5-year DFS and OS. Furthermore, we determined the cutoff values of the predicted scores for differentiating patients to low-risk, intermediate-risk, and high-risk groups using the X-tile software program (Yale University, New Haven, CT, USA [27]) based on the maximal chi-square test by grouping all the patients into distinct risk groups after 
Table 2 Univariable and multivariable analysis of training set for DFS

\begin{tabular}{|c|c|c|c|c|c|c|c|}
\hline \multirow[b]{2}{*}{ Variable } & \multirow{2}{*}{$\begin{array}{l}\text { Univariable } \\
\text { an- alysis } P\end{array}$} & \multicolumn{3}{|c|}{ Multivariable analysis } & \multicolumn{3}{|c|}{ Selected factors for building the nomogram } \\
\hline & & $\mathrm{HR}$ & $95 \% \mathrm{Cl}$ & $P$ & $\mathrm{HR}$ & $95 \% \mathrm{Cl}$ & $P$ \\
\hline Grade & 0.024 & & & & & & \\
\hline 1 & & Ref & & & & & \\
\hline$\|$ & & 0.889 & $0.108-7.308$ & 0.913 & & & \\
\hline III & & 1.477 & $0.193-11.297$ & 0.707 & & & \\
\hline Tumor size & $<0.001$ & & & & & & \\
\hline$\leq 2 \mathrm{~cm}$ & & Ref & & & Ref & & \\
\hline $2-5 \mathrm{~cm}$ & & 2.010 & $1.168-3.456$ & 0.012 & 1.912 & $1.156-3.163$ & 0.012 \\
\hline$>5 \mathrm{~cm}$ & & 3.481 & $1.578-7.675$ & 0.002 & 3.319 & $1.526-7.217$ & 0.002 \\
\hline Node status & $<0.001$ & & & & & & \\
\hline No & & Ref & & & Ref & & \\
\hline N1 & & 1.464 & $0.789-2.716$ & 0.227 & 1.628 & $0.933-2.843$ & 0.086 \\
\hline $\mathrm{N} 2+\mathrm{N} 3$ & & 3.613 & $2.043-6.390$ & $<0.001$ & 3.784 & $2.173-6.589$ & $<0.001$ \\
\hline Ki67 index & 0.018 & & & & & & \\
\hline$<40 \%$ & & Ref & & & Ref & & \\
\hline$\geq 40 \%$ & & 1.977 & $1.179-3.314$ & 0.010 & 2.166 & $1.310-3.583$ & 0.003 \\
\hline sTIL group (\%) & 0.002 & & & & & & \\
\hline $0-9$ & & Ref & & & Ref & & \\
\hline $10-19$ & & 0.436 & $0.238-0.801$ & 0.007 & 0.432 & $0.240-0.778$ & 0.005 \\
\hline $20-49$ & & 0.383 & $0.200-0.734$ & 0.004 & 0.390 & $0.207-0.734$ & 0.004 \\
\hline$\geq 50$ & & 0.305 & $0.148-0.631$ & 0.001 & 0.308 & $0.154-0.616$ & 0.001 \\
\hline Surgery type & 0.247 & & & & & & \\
\hline \multicolumn{8}{|l|}{ Mastectomy } \\
\hline \multicolumn{8}{|l|}{ Lumpectomy } \\
\hline Radiotherapy & 0.144 & & & & & & \\
\hline \multicolumn{8}{|l|}{ Yes } \\
\hline \multicolumn{8}{|l|}{ No } \\
\hline Age & 0.886 & & & & & & \\
\hline \multicolumn{8}{|l|}{$\leq 35$} \\
\hline \multicolumn{8}{|l|}{$36-50$} \\
\hline \multicolumn{8}{|l|}{$>50$} \\
\hline Marital status & 0.753 & & & & & & \\
\hline \multicolumn{8}{|l|}{ Married } \\
\hline \multicolumn{8}{|l|}{ Unmarried } \\
\hline Family history of breast cancer & 0.785 & & & & & & \\
\hline \multicolumn{8}{|l|}{ Yes } \\
\hline \multicolumn{8}{|l|}{ No } \\
\hline Menopausal status & 0.911 & & & & & & \\
\hline \multicolumn{8}{|l|}{ Premenopausal } \\
\hline \multicolumn{8}{|l|}{ Postmenopausal } \\
\hline Histology & 0.655 & & & & & & \\
\hline \multicolumn{8}{|l|}{ Ductal } \\
\hline \multicolumn{8}{|l|}{ Lobular/other } \\
\hline Chemotherapy type & 0.134 & & & & & & \\
\hline
\end{tabular}


Table 2 Univariable and multivariable analysis of training set for DFS (Continued)

\begin{tabular}{|c|c|c|c|c|c|c|c|}
\hline \multirow[b]{2}{*}{ Variable } & \multirow{2}{*}{$\begin{array}{l}\text { Univariable } \\
\text { an- alysis } P\end{array}$} & \multicolumn{3}{|c|}{ Multivariable analysis } & \multicolumn{3}{|c|}{ Selected factors for building the nomogram } \\
\hline & & $\mathrm{HR}$ & $95 \% \mathrm{Cl}$ & $P$ & $\mathrm{HR}$ & $95 \% \mathrm{Cl}$ & $P$ \\
\hline \multicolumn{8}{|l|}{ Neoadjuvant } \\
\hline \multicolumn{8}{|l|}{ Adjuvant } \\
\hline \multicolumn{8}{|l|}{ No chemotherapy } \\
\hline Chemotherapy regimen & 0.0019 & & & & & & \\
\hline anthracycline-based & & Ref & & & & & \\
\hline taxane-based & & 1.239 & $0.667-2.300$ & 0.497 & & & \\
\hline anthracycline\& taxane -based & & 0.791 & $0.444-1.409$ & 0.426 & & & \\
\hline
\end{tabular}

Abbreviations: DFS disease-free survival, $H R$ hazard ratio, $C l$ confidence interval, Ref reference, sTIL stromal tumor-infiltrating lymphocyte

sorting by total score. To avoid the problem of multiple cut-point selection, X-tile can produce corrected $P$ values using several Monte Carlo simulations. And the respective Kaplan-Meier curves were then delineated. Statistical analyses and modeling were performed using STATA (version 13; Stata Co., College Station, TX), and R software packages. All statistical tests were two-sided, and statistical significance was defined as $P<0.05$.

\section{Results}

\section{Study population characteristics}

The training population included 296 invasive nonmetastastic TNBC women treated at Sun Yat-sen Memorial Hospital with a median follow-up of 52.5 months. There were 78 DFS events, and 46 deaths during the follow-up period for training cohort. Independent validation cohorts were compromised of 191 women diagnosed with operable invasive TNBC in the second Xiangya Hospital $(n=144)$ and Peking University Shenzhen Hospital $(n=47)$ over a median follow-up of
68 months. A total of 51 DFS events and 32 deaths occurred in the validation population. Some collected variables (grade, and Ki67 index) contained missing data (less than 20\%), so multiple imputation was performed before nomogram development and validation to account for the missing values of these variables. Demographic and clinicopathological characteristics of patients in the training and validation cohorts before and after multiple imputations are shown in Table 1.

\section{Prognostic nomogram for DFS}

In the training set, DFS curves for different demographic, clinicopathological and treatment factor values were generated by the Kaplan-Meier estimates and were compared by log-rank test. The variables that selected in the final multivariable Cox regression model were stromal TILs, tumor size, node status, and Ki67 index (Table 2). A nomogram that incorporated these four prognostic variables was then developed (Fig. 1a), and we named this nomogram as triple-negative recurrence

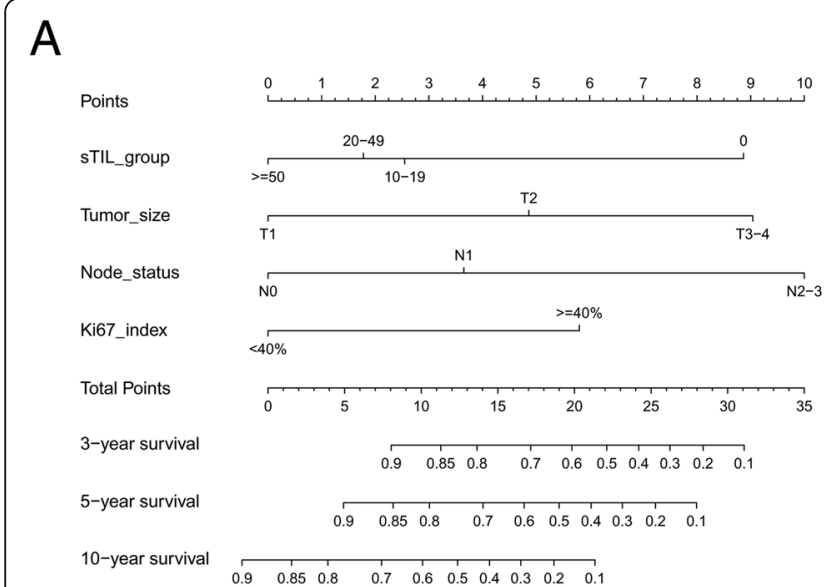

B

Points
STIL_group
Tumor_size
Node_status
Ki67_index
Total Points
3-year survival
5-year survival
10-year survival
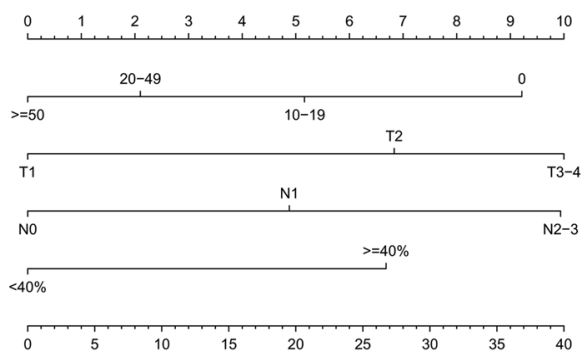

0

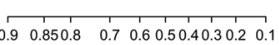

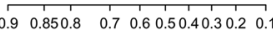

Fig. 1 Prognostic nomograms for predicting (a) DFS and (b) OS of patients with non-metastatic TNBC (When using these nomograms, individual patient's value will be located on each variable axis, and a line will be drawn to determine the scores received for each variable value. Sum of the scores will then be located on the Total Points axis. According to the scores, we may predict the 3 year-, 5 year-, and 10 year-DFS or OS for this individual) 
(TNR). Each subtype within these variables was assigned a score on the point scale (Additional file 1: Table S1.). Briefly, we can put the specific values of a TNBC patient into the TNR nomogram, and then calculated a score for this patient. According to the score, we may predict the 3 year- and 5 year-DFS for this individual. Ideal concordance in AUC was observed for the nomogram in both training and validation cohort with $\mathrm{C}$-index of 0.743 and 0.784 , respectively, and AUC of 0.777 and 0.783 (Fig. 2), respectively.

\section{Prognostic nomogram for OS}

In the training set, OS curves for different demographic, clinicopathological and treatment variable values (the same variables in the DFS nomogram initiating) were generated. The variables in the final multivariable Cox regression model were stromal TILs, tumor size, node status, and Ki67 index (Table 3). A nomogram that incorporated these four prognostic variables was then developed (Fig. 1b), and the model was named as triple-negative survival (TNS). Each subtype within these variables was assigned a score on the point scale (Additional file 1: Table S1.). Briefly, when using the nomogram, we can put the specific values of a TNBC patient into the TNS nomogram, and then calculated a score for this patient. According to the score, we may predict the 3 year- and 5 year-OS for this individual. Ideal concordance in AUC was observed for the nomogram in both training and validation cohort with C-index of 0.791 and 0.783 , respectively, and AUC of 0.813 and 0.784 (Fig. 3), respectively.

\section{Calibration of nomograms and comparison with AJCC staging、PREDICT and CancerMath}

An acceptable agreement of the calibration plots was found both in the training and validation cohorts between the model prediction and actual data for 3-, and 5-year DFS and OS (Additional file 2: Figure S1). In the training cohort, the C-index for our model to predict DFS (0.743, 95\% CI 0.692-0.794) was significantly better than that of the seventh and eighth AJCC TNM staging system (0.666, 95\% CI 0.611-0.721, $P=0.003 ; 0.664,95 \%$ CI 0.605-0.723, $P=0.024)$; and the $\mathrm{C}$-index to predict OS $(0.791,95 \% \mathrm{CI}$ 0.735-0.847) was statistically greater than that of the TNM systems $(0.683,95 \%$ CI $0.613-0.753, \quad P=0.004$; $0.677,95 \%$ CI $0.606-0.748, P<0.001)$ as well. Similarly, in the validation cohort, the $\mathrm{C}$-index of our model to predict DFS (0.784, 95\% CI 0.724-0.844) was much higher than that of the seventh and eighth TNM systems $(0.632,95 \%$ CI $0.518-0.746, P=0.02$; 0.607, 95\% CI 0.554-0.660, $P=$ 0.002); and the $\mathrm{C}$-index to predict OS was also better for our nomogram prediction $(0.783$, 95\% CI $0.705-0.861)$ than for the TNM systems prediction $(0.656,95 \% \mathrm{CI}$ $0.516-0.796, P=0.006 ; 0.606$, 95\% CI 0.535-0.677, $P=$ $0.001)$. Furthermore, we compared the predictive accuracy and discriminative ability of our nomograms with two classical breast cancer models. The AUC for OS was 0.813 in the training and 0.784 in the validation cohort, respectively, which was larger than the AUCs of 0.752 and 0.767 in training and 0.766 and 0.751 in validation for PREDICT and CancerMath, respectively (Fig. 3).

\section{Performance of the nomogram in stratifying risk of patients}

We then defined the cutoff values using X-tile software program by grouping patients in the training cohort into three groups after sorting by total DFS or OS score (Additional file 1: Table S1.). Each group showed significantly different survival outcomes (Additional file 1: Table S1., Fig. 4a and b). These cutoff values also well
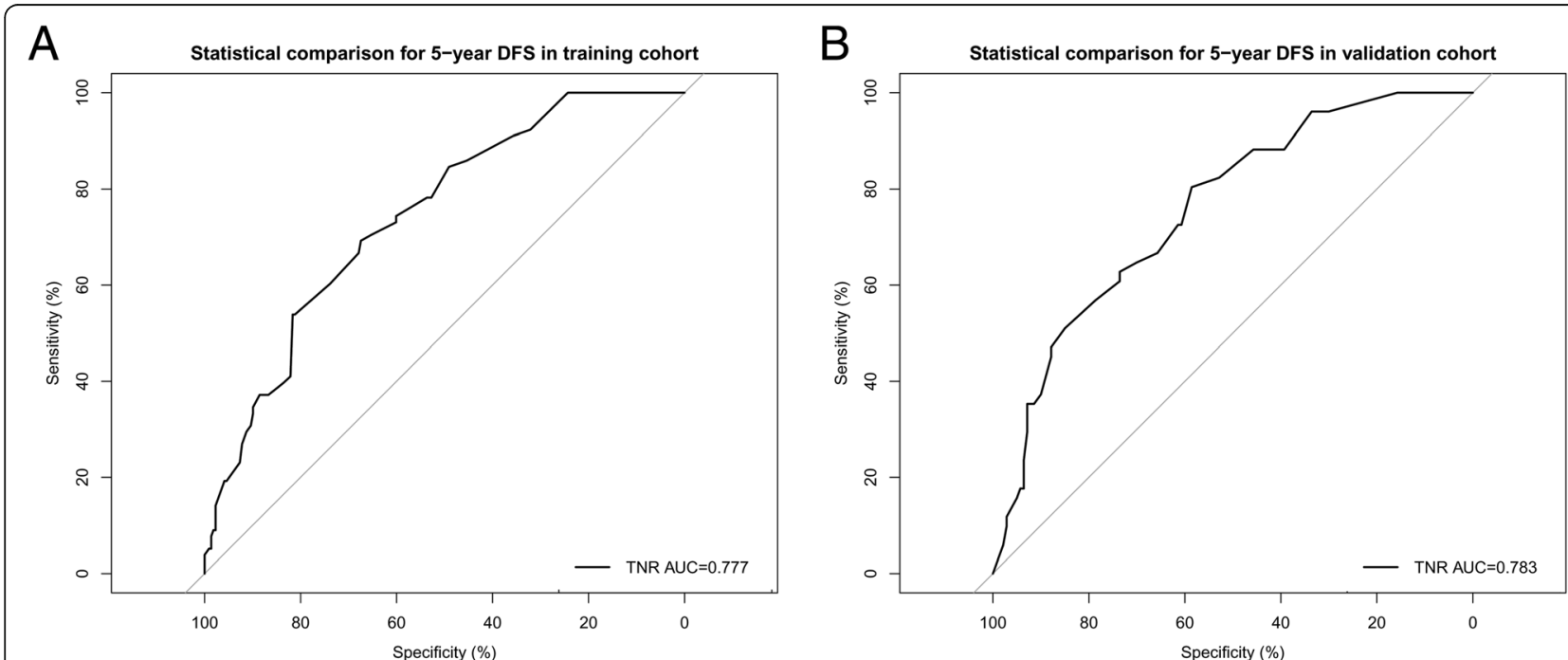

Fig. 2 Discriminatory accuracy for predicting DFS assessed by receiver operator characteristics analysis calculating AUC. 5-year DFS in the a) training cohort and $\mathbf{b}$ ) validation cohort. TNR = triple-negative recurrence; $A U C=$ area under the curve 
Table 3 Univariable and multivariable analysis of training set for OS

\begin{tabular}{|c|c|c|c|c|c|c|c|}
\hline \multirow[b]{2}{*}{ Variable } & \multirow{2}{*}{$\begin{array}{l}\text { Univariable } \\
\text { an- alysis } P\end{array}$} & \multicolumn{3}{|c|}{ Multivariable analysis } & \multicolumn{3}{|c|}{ Selected factors for building the nomogram } \\
\hline & & $\mathrm{HR}$ & $95 \% \mathrm{Cl}$ & $P$ & $\mathrm{HR}$ & $95 \% \mathrm{Cl}$ & $P$ \\
\hline Grade & 0.032 & & & & & & \\
\hline 1 & & Ref & & & & & \\
\hline$\|$ & & 0.151 & $0.014-1.605$ & 0.117 & & & \\
\hline III & & 0.461 & $0.055-3.876$ & 0.476 & & & \\
\hline Tumor size & $<0.001$ & & & & & & \\
\hline$\leq 2 \mathrm{~cm}$ & & Ref & & & Ref & & \\
\hline $2-5 \mathrm{~cm}$ & & 3.226 & $1.541-6.755$ & 0.002 & 2.981 & $1.516-5.864$ & 0.002 \\
\hline$>5 \mathrm{~cm}$ & & 4.704 & $1.587-13.939$ & 0.005 & 4.916 & $1.705-14.174$ & 0.003 \\
\hline Node status & $<0.001$ & & & & & & \\
\hline NO & & Ref & & & Ref & & \\
\hline N1 & & 2.121 & $0.941-4.778$ & 0.070 & 2.183 & $1.050-4.559$ & 0.037 \\
\hline $\mathrm{N} 2+\mathrm{N} 3$ & & 4.545 & $2.086-9.902$ & $<0.001$ & 4.900 & $2.328-10.312$ & $<0.001$ \\
\hline Ki67 index & 0.018 & & & & & & \\
\hline$<40 \%$ & & Ref & & & Ref & & \\
\hline$\geq 40 \%$ & & 2.778 & $1.339-5.763$ & 0.006 & 2.906 & $1.440-5.863$ & 0.003 \\
\hline sTIL group (\%) & 0.025 & & & & & & \\
\hline $0-9$ & & Ref & & & Ref & & \\
\hline $10-19$ & & 0.578 & $0.269-1.240$ & 0.159 & 0.523 & $0.252-1.085$ & 0.082 \\
\hline $20-49$ & & 0.272 & $0.108-0.686$ & 0.006 & 0.320 & $0.134-0.767$ & 0.011 \\
\hline$\geq 50$ & & 0.217 & $0.075-0.629$ & 0.005 & 0.230 & $0.082-0.645$ & 0.005 \\
\hline Surgery type & 0.198 & & & & & & \\
\hline \multicolumn{8}{|l|}{ Mastectomy } \\
\hline \multicolumn{8}{|l|}{ Lumpectomy } \\
\hline Radiotherapy & 0.315 & & & & & & \\
\hline \multicolumn{8}{|l|}{ Yes } \\
\hline \multicolumn{8}{|l|}{ No } \\
\hline Age & 0.392 & & & & & & \\
\hline \multicolumn{8}{|l|}{$\leq 35$} \\
\hline \multicolumn{8}{|l|}{$36-50$} \\
\hline \multicolumn{8}{|l|}{$>50$} \\
\hline Marital status & 0.588 & & & & & & \\
\hline \multicolumn{8}{|l|}{ Married } \\
\hline \multicolumn{8}{|l|}{ Unmarried } \\
\hline Family history of breast cancer & 0.274 & & & & & & \\
\hline \multicolumn{8}{|l|}{ Yes } \\
\hline \multicolumn{8}{|l|}{ No } \\
\hline Menopausal status & 0.107 & & & & & & \\
\hline \multicolumn{8}{|l|}{ Premenopausal } \\
\hline \multicolumn{8}{|l|}{ Postmenopausal } \\
\hline Histology & 0.224 & & & & & & \\
\hline \multicolumn{8}{|l|}{ Ductal } \\
\hline \multicolumn{8}{|l|}{ Lobular/other } \\
\hline Chemotherapy type & 0.374 & & & & & & \\
\hline
\end{tabular}


Table 3 Univariable and multivariable analysis of training set for OS (Continued)

\begin{tabular}{|c|c|c|c|c|c|c|c|}
\hline \multirow[b]{2}{*}{ Variable } & \multirow{2}{*}{$\begin{array}{l}\text { Univariable } \\
\text { an- alysis } P\end{array}$} & \multicolumn{3}{|c|}{ Multivariable analysis } & \multicolumn{3}{|c|}{ Selected factors for building the nomogram } \\
\hline & & $\mathrm{HR}$ & $95 \% \mathrm{Cl}$ & $P$ & $\mathrm{HR}$ & $95 \% \mathrm{Cl}$ & $P$ \\
\hline \multicolumn{8}{|l|}{ Neoadjuvant } \\
\hline \multicolumn{8}{|l|}{ Adjuvant } \\
\hline \multicolumn{8}{|l|}{ No chemotherapy } \\
\hline Chemotherapy regimen & 0.046 & & & & & & \\
\hline anthracycline-based & & Ref & & & & & \\
\hline taxane-based & & 1.551 & $0.682-3.528$ & 0.296 & & & \\
\hline anthracycline\& taxane -based & & 0.781 & $0.371-1.643$ & 0.514 & & & \\
\hline
\end{tabular}

Abbreviations: OS overall survival, $H R$ hazard ratio, $C l$ confidence interval, Ref reference, sTIL stromal tumor-infiltrating lymphocyte

differentiated patients in the validation cohort to low-risk, intermediate-risk, and high-risk groups with extremely distinct prognosis (Fig. 4c and d).

\section{Discussion}

To the best of our knowledge, this is the first study that incorporates stromal TILs into clinicopathological variables in predicting prognosis for TNBC patients. Our nomograms, named as TNR and TNS, which were developed using the Chinese TNBC patients treated at Sun Yat-sen Memorial Hospital, showed AUCs of 0.777 for DFS and 0.813 for OS in the training cohort. The discriminatory accuracy of TNR/TNS was then validated in independent external validation patient population from the second Xiangya Hospital and Peking University Shenzhen Hospital by AUCs of 0.783 for DFS and 0.784 for OS. In addition, our nomograms showed significantly higher C-index than that of the seventh and eighth AJCC TNM staging system in predicting DFS and OS; and larger AUCs compared with the classical prognostic models including PREDICT and CancerMath, although the improvement was little.

When assessing the outcomes and risk of breast cancer, predictive nomograms are useful tools. Lots of such models have been developed based on clinicopathological and receptors statuses [4-14]. Nevertheless, majority of these models were developed based on white patients from American and European countries, and many nomograms focused on OS or breast cancer specific survival (BCSS), but not DFS. One nomogram [13] can predict recurrence risk, but it may not be generalizable to external populations because it was developed using patients from a famous large single institution (MD Anderson Cancer Center) that may bring potential referral and therapeutic bias. As we known, the clinicopathological features and prognosis of breast cancer may vary by race/ethnicity. For instance, the average age of onset for Asian women was approximately 10 years younger than that for western women [28-33]. Therefore, the majority of these models that
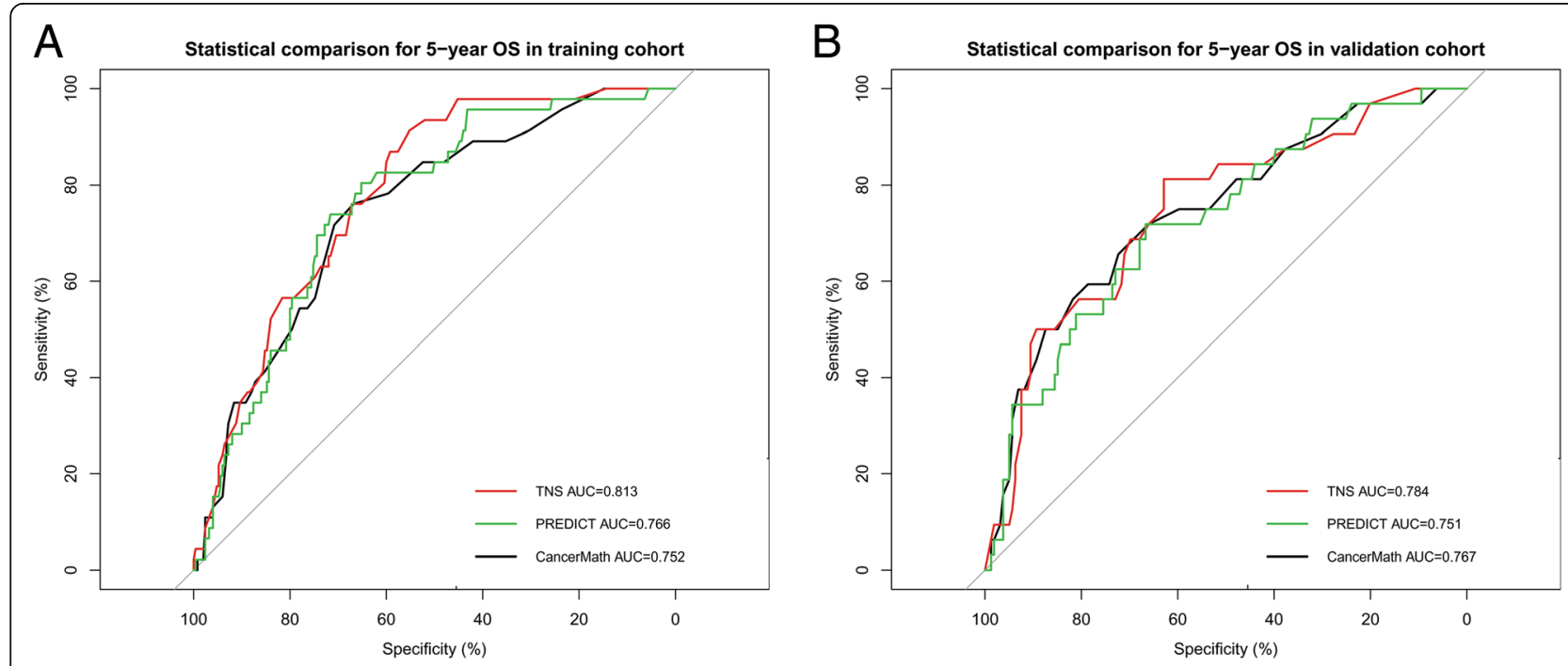

Fig. 3 Discriminatory accuracy for predicting OS assessed by receiver operator characteristics analysis calculating AUC. 5-year OS in the a) training cohort and $\mathbf{b}$ ) validation cohort. TNS = triple-negative survival; AUC = area under the curve 


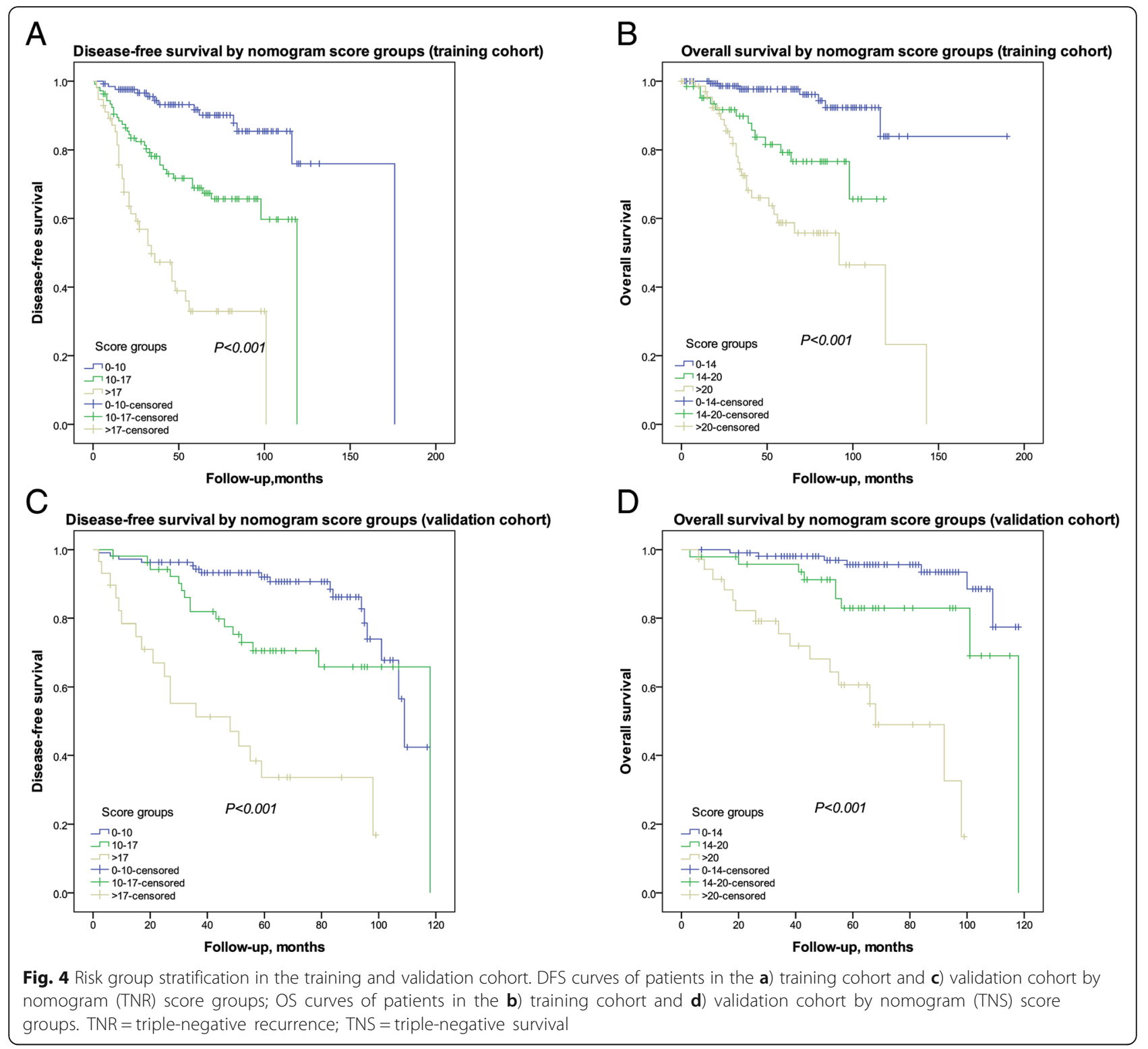

were developed based on western patients may have limited value in Asian breast cancer patients. There is a nomogram developed from Taiwanese women, however, it can only predict OS for patients treated with mastectomy [12]. Furthermore, the prognostic values of these existing models were only tested in a few cohorts of TNBC $[6,13,15]$, which is a heterogeneous disease comprised of several distinct subtypes with totally different prognosis. A potential predictive model for TNBC based on simple sum of $\geq 4$ positive lymph nodes, positive Cathepsin-D expression and Ki-67 index $\geq 20 \%$ has been reported previously [34]. However, the score for each variable was not well justified, and the model included patients only from a single institution. Moreover, it showed smaller AUCs for predicting survival both in the training (0.696) and validation set (0.717) compared with our model.

Further, compared with existing nomograms, TNR/ TNS incorporated several new and potentially universal predictive or prognostic factors for TNBC including stromal TILs and Ki67 index. The prognostic significance of TILs in TNBC has been recently demonstrated in a number of randomized clinical trials, both in the neoadjuvant and adjuvant settings [16-19]. The International TIL Working Group released detailed guidelines in 2014 for harmonizing TILs assessment in routine samples [23]. In this study, we assessed the stromal TILs strictly by applying the recent International TILWG guidelines. For the first time, we developed and validated nomograms predicting outcomes in TNBC by 
incorporating stromal TILs into the models. Additionally, previous studies have demonstrated that TNBC with higher Ki-67 index is associated with larger tumor size, more positive nodes, and worse prognosis [35, 36]. Our findings suggested that Ki-67 index $\geq 40 \%$ may be adequate to demonstrate an association with recurrence and unfavorable survival in TNBC.

Despite above strengths, our nomograms are limited by the retrospective nature of data collection and relatively small sample size. Some of the calibration plots for the validation cohort were less than ideal, which is another limitation of this study. Also, the TNR and TNS were based on Chinese TNBC patients, therefore it is not clear whether they can be applied to western patient cohorts or not. Further efforts on prospective data collection, larger patient cohorts, and validation in other geographic patient populations are needed to improve our nomograms.

\section{Conclusions}

We have developed and validated novel, well-calibrated nomograms for predicting DFS and OS in non-metastatic Chinese TNBC patients by including stromal TILs for the first time. These prognostic nomograms can help clinicians in risk consulting/management and selection of long term survivors among TNBC patients. Additional studies are required to identify whether they can be applied to other geographic patient populations.

\section{Additional files}

Additional file 1: Table S1. The calibration curves for predicting patient survival at each time point in the training and validation cohort. A) 3-year and B) 5-year DFS in the training cohort; C) 3-year and D) 5-year OS in the training cohort; E) 3-year and F) 5-year DFS in the validation cohort; G) 3-year and H) 5-year OS in the validation cohort. (TIF $3422 \mathrm{~kb}$ )

Additional file 2: Figure S1. Point assignment and prognostic score for DFS and OS. (DOCX $15 \mathrm{~kb})$

\begin{abstract}
Abbreviations
AJCC: American Joint Committee on Cancer; AUC: area under the curve; Cindex: concordance index; DFS: disease-free survival; ER: estrogen receptor; H\&E: hematoxylin and eosin; HER2: human epidermal growth factor receptor 2; OS: overall survival; PR: progesterone receptor; ROC: receiver operating characteristic; TILs: tumor-infiltrating lymphocytes; TNBC: Triple negative breast cancer; TNR: triple-negative recurrence; TNS: triple-negative survival
\end{abstract}

\section{Acknowledgements}

We thank all the patients who agreed to participate in this study. This work was supported by the National Natural Science Foundation of China (81602673); Key Laboratory of Malignant Tumor Molecular Mechanism and Translational Medicine of Guangzhou Bureau of Science and Information Technology ([2013]163); Key Laboratory of Malignant Tumor Gene Regulation and Target Therapy of Guangdong Higher Education Institutes (KLB09001).

\section{Funding}

This work was supported by the National Natural Science Foundation of China (81602673) (for pathologic slides preparing, IHC staining, and follow-up of patients); Key Laboratory of Malignant Tumor Molecular Mechanism and Translational Medicine of Guangzhou Bureau of Science and Information
Technology ([2013]163) (for data collection and dataset build up); Key Laboratory of Malignant Tumor Gene Regulation and Target Therapy of Guangdong Higher Education Institutes (KLB09001) (for data analysis).

\section{Availability of data and materials}

The datasets used and analyzed during the current study are available from the corresponding author on reasonable request.

\section{Authors' contributions}

YPY, CT, QL, ZHH, WW and EXZ participated in the data collection and assembly of data. YPY, JQL and YW carried out the statistical analysis and drafted the manuscript. JQL, YPY, WW and HRD conceived of the study, and participated in its design and drafted the manuscript. JQL and QLU participated in the manuscript revision. All authors read and approved the final manuscript.

\section{Ethics approval and consent to participate}

Ethical approval was obtained from participating institutions through their respective institutional review boards (IRB) (Sun Yat-sen Memorial Hospital Ethics Committee and IRB, Ethics Committee and IRB of Peking University Shenzhen Hospital, and Ethics Committee and IRB of the Second Xiangya Hospital, Central South University), and written informed consent was obtained from study participants.

\section{Consent for publication}

Not applicable.

\section{Competing interests}

The authors declare that they have no competing interests.

\section{Publisher's Note}

Springer Nature remains neutral with regard to jurisdictional claims in published maps and institutional affiliations.

\section{Author details}

'Guangdong Provincial Key Laboratory of Malignant Tumor Epigenetics and Gene Regulation, Breast Tumor Center, Sun Yat-sen Memorial Hospital, Sun Yat-sen University, Yanjiang West Road 107\#, Guangzhou 510120, China. ${ }^{2}$ Guangdong Provincial Key Laboratory of Malignant Tumor Epigenetics and Gene Regulation, Department of Pathology, Sun Yat-sen Memorial Hospital, Sun Yat-sen University, Guangzhou, China. ${ }^{3}$ Department of Breast and Thyroid Surgery, Peking University Shenzhen Hospital, Shenzhen, China. ${ }^{4}$ Department of Breast and Thyroid Surgery, the Second Xiangya Hospital, Central South University, Changsha, Hunan, China.

Received: 25 April 2018 Accepted: 10 May 2019 Published online: 06 June 2019

\section{References}

1. Denkert C, Liedtke C, Tutt A, von Minckwitz G. Molecular alterations in triple-negative breast cancer-the road to new treatment strategies. Lancet. 2017;389(10087):2430-42.

2. Bianchini G, Balko JM, Mayer IA, Sanders ME, Gianni L. Triple-negative breast cancer: challenges and opportunities of a heterogeneous disease. Nat Rev Clin Oncol. 2016;13(11):674-90.

3. Lehmann BD, Bauer JA, Chen $X$, Sanders ME, Chakravarthy AB, Shyr $Y$, Pietenpol JA. Identification of human triple-negative breast cancer subtypes and preclinical models for selection of targeted therapies. J Clin Invest. 2011;121(7):2750-67.

4. Haybittle JL, Blamey RW, Elston CW, Johnson J, Doyle PJ, Campbell FC, Nicholson Rl, Griffiths K. A prognostic index in primary breast cancer. $\mathrm{Br}$ J Cancer. 1982;45(3):361-6.

5. Ravdin PM, Siminoff LA, Davis GJ, Mercer MB, Hewlett J, Gerson N, Parker HL. Computer program to assist in making decisions about adjuvant therapy for women with early breast cancer. J Clin Oncol. 2001;19(4):980-91.

6. Wishart GC, Azzato EM, Greenberg DC, Rashbass J, Kearins O, Lawrence G, Caldas C, Pharoah PD. PREDICT: a new UK prognostic model that predicts survival following surgery for invasive breast cancer. Breast Cancer Res. 2010;12(1):R1.

7. Wishart GC, Bajdik CD, Dicks E, Provenzano E, Schmidt MK, Sherman M, Greenberg DC, Green AR, Gelmon KA, Kosma VM, et al. PREDICT plus: 
development and validation of a prognostic model for early breast cancer that includes HER2. Br J Cancer. 2012;107(5):800-7.

8. Kim W, Kim KS, Lee JE, Noh DY, Kim SW, Jung YS, Park MY, Park RW. Development of novel breast cancer recurrence prediction model using support vector machine. J Breast Cancer. 2012;15(2):230-8.

9. Michaelson JS, Chen LL, Bush D, Fong A, Smith B, Younger J. Improved web-based calculators for predicting breast carcinoma outcomes. Breast Cancer Res Treat. 2011;128(3):827-35.

10. Mazouni C, Spyratos F, Romain S, Fina F, Bonnier P, Ouafik LH, Martin PM. A nomogram to predict individual prognosis in node-negative breast carcinoma. Eur J Cancer. 2012;48(16):2954-61.

11. Campbell HE, Gray AM, Harris AL, Briggs AH, Taylor MA. Estimation and external validation of a new prognostic model for predicting recurrencefree survival for early breast cancer patients in the UK. Br J Cancer. 2010; 103(6):776-86

12. Fan YP, Liu CL, Chiang IJ, Lin CY. Development of a prognostic nomogram for identifying those factors which influence the 2- and 5-year survival chances of Taiwanese women diagnosed with breast cancer. Eur J Cancer Care. 2011;20(5):620-6.

13. Wu X, Ye Y, Barcenas CH, Chow WH, Meng QH, Chavez-MacGregor M, Hildebrandt MA, Zhao H, Gu X, Deng Y, et al. Personalized prognostic prediction models for breast Cancer recurrence and survival incorporating multidimensional data. J Natl Cancer Inst. 2017;109(7).

14. Candido Dos Reis FJ, Wishart GC, Dicks EM, Greenberg D, Rashbass J, Schmidt MK, van den Broek AJ, Ellis IO, Green A, Rakha E, et al. An updated PREDICT breast cancer prognostication and treatment benefit prediction model with independent validation. Breast Cancer Res. 2017;19(1):58.

15. Albergaria A, Ricardo S, Milanezi F, Carneiro V, Amendoeira I, Vieira D, Cameselle-Teijeiro J, Schmitt F. Nottingham prognostic index in triplenegative breast cancer: a reliable prognostic tool? BMC Cancer. 2011;11:299.

16. Denkert C, Loibl S, Noske A, Roller M, Muller BM, Komor M, Budczies J, DarbEsfahani S, Kronenwett R, Hanusch C, et al. Tumor-associated lymphocytes as an independent predictor of response to neoadjuvant chemotherapy in breast cancer. J Clin Oncol. 2010;28(1):105-13.

17. Loi S, Sirtaine N, Piette F, Salgado R, Viale G, Van Eenoo F, Rouas G, Francis $P$, Crown JP, Hitre $E$, et al. Prognostic and predictive value of tumorinfiltrating lymphocytes in a phase III randomized adjuvant breast cancer trial in node-positive breast cancer comparing the addition of docetaxel to doxorubicin with doxorubicin-based chemotherapy: BIG 02-98. J Clin Oncol. 2013;31(7):860-7.

18. Loi S, Michiels S, Salgado R, Sirtaine N, Jose V, Fumagalli D, KellokumpuLehtinen PL, Bono P, Kataja V, Desmedt $C$, et al. Tumor infiltrating lymphocytes are prognostic in triple negative breast cancer and predictive for trastuzumab benefit in early breast cancer: results from the FinHER trial. Ann Oncol. 2014:25(8):1544-50.

19. Adams S, Gray RJ, Demaria S, Goldstein L, Perez EA, Shulman LN, Martino S, Wang M, Jones VE, Saphner TJ, et al. Prognostic value of tumor-infiltrating lymphocytes in triple-negative breast cancers from two phase III randomized adjuvant breast cancer trials: ECOG 2197 and ECOG 1199. J Clin Oncol. 2014;32(27):2959-66.

20. Klebanoff MA, Cole SR. Use of multiple imputation in the epidemiologic literature. Am J Epidemiol. 2008;168(4):355-7.

21. Janssen KJ, Donders AR, Harrell FE Jr, Vergouwe Y, Chen Q, Grobbee DE, Moons KG. Missing covariate data in medical research: to impute is better than to ignore. J Clin Epidemiol. 2010;63(7):721-7.

22. Liao SG, Lin Y, Kang DD, Chandra D, Bon J, Kaminski N, Sciurba FC, Tseng GC. Missing value imputation in high-dimensional phenomic data: imputable or not, and how? BMC bioinformatics. 2014;15:346.

23. Salgado $R$, Denkert $C$, Demaria $S$, Sirtaine N, Klauschen F, Pruneri G, Wienert $\mathrm{S}$, Van den Eynden G, Baehner FL, Penault-Llorca F, et al. The evaluation of tumor-infiltrating lymphocytes (TILS) in breast cancer: recommendations by an international TILs working group 2014. Ann Oncol. 2015;26(2):259-71.

24. Liang W, Zhang L, Jiang G, Wang Q, Liu L, Liu D, Wang Z, Zhu Z, Deng Q, Xiong $X$, et al. Development and validation of a nomogram for predicting survival in patients with resected non-small-cell lung cancer. J Clin Oncol. 2015;33(8):861-9.

25. Harrell FE Jr. Regression Modeling Strategies. New York: Springer -Verlag; 2001

26. Hanley JA, MCNeil BJ. A method of comparing the areas under receiver operating characteristic curves derived from the same cases. Radiology. 1983;148(3):839-43.
27. Camp RL, Dolled-Filhart M, Rimm DL. X-tile: a new bio-informatics tool for biomarker assessment and outcome-based cut-point optimization. Clin Cancer Res. 2004;10(21):7252-9.

28. Fan L, Strasser-Weippl K, Li JJ, St Louis J, Finkelstein DM, Yu KD, Chen WQ, Shao ZM, Goss PE. Breast cancer in China. Lancet Oncol. 2014;15(7):e279-89.

29. Kang SY, Kim YS, Kim Z, Kim HY, Lee SK, Jung KW, Youn HJ. Basic findings regarding breast Cancer in Korea in 2015: data from a breast Cancer registry. J Breast Cancer. 2018;21(1):1-10.

30. Ko BS, Noh WC, Kang SS, Park BW, Kang EY, Paik NS, Yang JH, Ahn SH. Changing patterns in the clinical characteristics of korean breast cancer from 1996-2010 using an online nationwide breast cancer database. J Breast Cancer. 2012;15(4):393-400.

31. Kuo WH, Yen AM, Lee PH, Chen KM, Wang J, Chang KJ, Chen TH, Tsau HS Cumulative survival in early-onset unilateral and bilateral breast cancer: an analysis of 1907 Taiwanese women. Br J Cancer. 2009;100(4):563-70.

32. Li J, Zhang BN, Fan JH, Pang Y, Zhang P, Wang SL, Zheng S, Zhang B, Yang $\mathrm{HJ}$, Xie XM, et al. A nation-wide multicenter 10-year (1999-2008) retrospective clinical epidemiological study of female breast cancer in China. BMC Cancer. 2011;11:364.

33. Lu WL, Li HX, Qian BY, Wang Y, Jansen L, Huang GW, Tang NJ, Sun Z, Chen $\mathrm{KX}$, De Bock GH. The clinical characteristics and prognosis of Chinese early stage breast cancer patients: a retrospective study. Breast J. 2010;16(3):331-3.

34. Huang L, Liu Z, Chen S, Liu Y, Shao Z. A prognostic model for triplenegative breast cancer patients based on node status, cathepsin-D and Ki67 index. PLoS One. 2013:8(12):e83081.

35. Rhee J, Han SW, Oh DY, Kim JH, Im SA, Han W, Park IA, Noh DY, Bang YJ, Kim TY. The clinicopathologic characteristics and prognostic significance of triple-negativity in node-negative breast cancer. BMC Cancer. 2008;8:307.

36. Keam B, Im SA, Lee KH, Han SW, Oh DY, Kim JH, Lee SH, Han W, Kim DW, Kim TY, et al. Ki-67 can be used for further classification of triple negative breast cancer into two subtypes with different response and prognosis. Breast Cancer Res. 2011;13(2):R22.

\section{Ready to submit your research? Choose BMC and benefit from:}

- fast, convenient online submission

- thorough peer review by experienced researchers in your field

- rapid publication on acceptance

- support for research data, including large and complex data types

- gold Open Access which fosters wider collaboration and increased citations

- maximum visibility for your research: over $100 \mathrm{M}$ website views per year

At BMC, research is always in progress.

Learn more biomedcentral.com/submissions 